the two sides of the Atlantic. After the International Conference of 1934 it was accepted by the U.S. Pharmacopøia Commission that the U.S.P. unit should have the same value as the international unit, 3,000 of each being contained in one gram of the U.S.P. reference cod liver oil. As has been shown above, the U.S.P. reference oil does not, in fact, contain as many as 3,000 1.U. per gm. The simplest solution would, therefore, appear to be to recognize that the U.S.P. and international units have not, after all, the same magnitude, but that the former is only $2,619 / 3,000$ or about $7 / 8$ of the latter and that the respective conversion factors are about 2,000 and about 1,740 .

This solution would leave the literature in some confusion, since the U.S.P. unit and the international unit have been regarded since the 1934 Conference as identical in value, and the terms as interchangeable, but the confusion does in any event exist and its existence is better recognized. In most of the work in which the confusion occurs, the magnitude of the discrepancy is not large enough to matter very much from the practical point of view. In connexion with commercial transactions where it is large enough to be important financially, agreement is in practice reached on the basis of concordant spectrophotometric determinations, but it is desirable that the exact nature and magnitude of this discrepancy should be recognized, and the position reviewed as evidence accumulates.

Those who took part in the work were: A. L. Bacharach, Glaxo Laboratories, Ltd., Greenford; W. A. Broom, Messrs. Boots Pure Drug Co., Ltd., Nottingham; H. M. Bruce and K. H. Coward, Pharmaceutical Society, London; A. D. Emmett and R. D. Brown, Messris. Parke, Davis and Co., Detroit Laboratories (communicated by J. A. Freeman); E. M. Hume, Lister Institute, London; J. O. Irwin, London School of Hygiene and Tropical Medicine; T. H. Mead and S. W. F. Underhill, Messrs. The British Drug Houses, Ltd., London ; 'T. Moore, Dunn Nutritional Laboratory, Cambridge; R. A. Morton. University, Liverpool ; W. Stott, British Cod Liver Oil Producers (Hull), Ltd.: H. Wilkinson, Lever Bros. and Unilever, Ltd., Port Sunlight.

E. M. Hume.

(Secretary, Vitamin A Sub-Committee of Accessory Food Factors Committee, appointed by the Lister Institute and Medical Research Council.) Lister Institute,

London, S.W.1.

1 NATURE, 139, 467 (1937).

NATURE, 143, 22 (1939).

Mead, T. H., Biochem. J., 33, 589 (1939).

- Hamano, S., Sci. Papers Inst. Phys. Chem. Res. Tokyo, 28, 69 (1935); 32, 44 (1937).

${ }^{5}$ Morton, R. A., Ann. Rev. Biochem., 11, 365 (1942).

\section{CARNEGIE CORPORATION OF NEW YORK}

$\mathrm{T}$ HE report of the Carnegie Corporation of New York for the year ending September 30, 1942, includes the report of the president, that of the secretary, with a list of appropriations authorized during the year, and the report of the treasurer.

In his first report as president, Mr. W. A. Jessup contrasts the present programme of the Corporation with that carried on during the War of 1914-18.
During that War, the Carnegie Corporation was scarcely more than an institutionalized extension of Mr. Carnegie's personal philanthropy. Its administrative machinery was new and its programme still in the making. Its direct contribution to the War took the form of generous gifts to outstanding private agencies which had undertaken to supply the amenities of life in the army camps. Appropriations to other Carnegie enterprises more actively concerned in the war effort and to the National Research Council were also voted.

Since 1918 the Corporation has granted $140,800,000$ dollars to various agencies and institutions which share its concern for the advancement and diffusion of knowledge, many of which are now in a position to render direct and useful services to the Government of the United States. Secondly, the public has been educated to support the social service agencies which were the chief recipients of grants made during 1917-18, and these agencies no longer look to the Corporation for any substantial proportion of their operating income. Moreover, the present War now involves the mobilization of the whole of the nation's intelligence, and under such conditions the Corporation, owing to its peculiarly close relations with men of science and scholars, can play a useful part within the terms of established policies.

Of the grants voted during the year 1941-42 totalling 2,831,650 dollars, 536,565 dollars have been given for activities directly related to the War. Of the new grants, the largest, 100,000 dollars, has enabled the Joint Army and Navy Committee on Welfare and Recreation to conduct experimental programmes as a basis for the growing activity of the Special Service Division of the War Department. Donations amounting to 12,500 dollars were made to the American Council of Education to keep colleges and universities informed of the needs in personnel of defence agencies and conversely to inform these agencies of the man-power resources of educational institutions. The three major grants to educational institutions during the year were to the new University Centre in Atalanta, the Johns Hopkins Univer. sity in Baltimore and the New York University. A grant of 10,000 dollars was voted for the formulation of special tests to be used in selecting personnel to be trained under the defence-training programme of the United States Office of Education. To prevent the curtailment of the services of the New York Academy of Medicine, an appropriation of 150,000 dollars was made to the Academy. Substantial endow. ment grants made to the National Academy of Sciences in earlier years have freed its operating arm, the National Research Council, from dependence on term grants, but in view of its new responsibilities the Trustees have voted a sum of 25,000 dollars to the National Academy in addition to the revolving fund of 100,000 dollars appropriated the preceding year.

Grants in support of the Social Science Research Council and the American Council of Learned Societies have also been renewed. These Councils have been the mainstay of the Government in staffing new defence bureaux and in prosecuting research to forward the war effort. The American Council of Education has served as a liaison agent between the Government and education, and the Social Science Research Council has assisted in the preliminary work on the national roster of specialized personnel and is serving as an advisor to the Government on many problems within the field of social science. On 
the other hand, the activities of the Committee on Scientific Aids to Learning have had to be suspended, and its director has been loaned to the Office of Scientific Research and Development, which is assuming much of the burden carried by the National Research Council during 1917-18. In view of the uncertainty now prevailing in world conditions, total appropriations from the British Dominions and Colonies Fund were less than in any year since 1927.

The report also includes a review of the contributions of the Corporation to the development of public and academic libraries and an analysis of a summary of the total grants made by the Corporation since 1911. Of this total of $185,000,000$ dollars, $70,000,000$ dollars were made to agencies or enterprises established by $\mathrm{Mr}$. Carnegie himself or growing immediately from them ; $48,000,000$ dollars to 848 universities, colleges and schools; 50,000,000 dollars to 777 associations, museums, libraries and agencies for research and study. More than 60 per cent of this 50 million dollars went to 22 agencies, particularly the National Academy of Sciences, including the National Research Council and the Committee on Scientific Aids to Learning (8,005,678 dollars), American Library Association (3,373,050 dollars), New York Academy of Medicine (1,625,190 dollars), American Council of Learned Societies (595,550 dollars) and Institute of International Education (1,354,979 dollars).

\section{MEASUREMENT OF LIGHTNING}

$\mathrm{N}$ an article on the measurement of lightning in 1 relation to telephone cables (Bell Lab. Rec., 21, No. 4 ; Dec. 1942), J. J. Mahoney, jun., describes some simple forms of apparatus used to ascertain the magnitude of lightning surges striking selected or other structures.

In a lightning prone area, near Lakewood, New Jersey, a number of steel masts were connected to about four miles of cable, buried for lightning tests in 1939 and not connected in any way to the Bell System plant. A tall steel mast is attached to the top of a wooden pole to direct lightning to buried telephone cables. The lightning current is conducted over a wire to an adjacent shorter pole on which measuring equipment is installed.

The tests include measurements of the crest value of the lightning current entering the cables, steepness of the wave front, the quantity of electricity in the lightning surge and the crest voltage across the insulation of the buried cable conductors. When plant damage occurs, an attempt is made to correlate it with the characteristics of the observed stroke. The ability of bare copper wires of various sizes to carry lightning current is being studied incidentally.

Since months may pass before a stroke is observed, simple inexpensive devices must be used. Their record is in the permanent magnetism given to them by the lightning. In one form, the magnetic links are straight pieces of laminated iron, each about $1 \frac{1}{2}$ in. long, enclosed in a Bakelite shell, mounted so as to intercept a magnetic field of greater or less strength, depending on their distance from the conductor, and so record currents from 500 to $10,000 \mathrm{amp}$. The links are calibrated in advance by determining the intensity of magnetization given to them by known currents.
The wave front steepness of a lightning surge is ascertained by inserting a magnetic link in a coil which is coupled with the lightning conductor. The apparatus has a rectangular loop of wire, one side of which is wound as a solenoid to enclose the link. When mounted a short distance from a conductor carrying a lightning surge, the link becomes magnetized and measures the peak current in the test circuit. From this and the crest value of the current in the lightning conductor, the time when the crest value of the discharge current is reached can be calculated from the resistive and inductive constants of the test circuit. Three loops are usually used at different distances from the conductor in order to increase accuracy of measurement.

The electrical charge of a lightning stroke is found by connecting a resistance in series with the lightning conductor and shunting an inductance across the resistance. The crest value of current in the inductance is measured by a magnetic link, and the charge then calculated from the product of the current and the inductance divided by the resistance. Peak voltages produced in telephone conductors by lightning are measured by a klydonograph, which consists of a blunt electrode in contact with the emulsion of a photographic plate backed with sheet metal and protected by a light-tight housing. The approximate magnitude and the polarity of the applied voltage can be determined by the size and appearance of the figure appearing on the developed plate. To measure the ability of lightning current to fuse bare copper wires of different gauges, several short lengths are connected in series on a terminal strip and inserted in the lead from each mast. Arcs between the ends of bent wires carry the discharge past test wires which have fused.

All the instruments used are simple to install, inexpensive and require no attention except that they are checked after each lightning storm by bringing a pocket compass near the links to test them for magnetism. Those found magnetized are removed for more accurate tests, and the photographic plates of the voltage recorders in the circuits affected are developed. The cable conductors are checked at the same time to detect plant damage.

Of three lightning strokes which have hit this experimental plant, only one struck a mast and splintered it slightly. This occurred in July 1939, before the buried cable and measuring equipment were installed. The second stroke came in October of the same year, striking a tree and entering a test cable near it by arcing from the tree's roots. The nearest measuring equipment, approximately $500 \mathrm{ft}$. away, recorded a crest current of 12,000 amp. The cable was considerably damaged. A third stroke occurred in July 1941. It also hit a tree and the lightning current entered the same cable through tree roots. Peak currents from this stroke varied from about 1,600 to $11,000 \mathrm{amp}$. at different points of the installation. Voltages ranged from 2 to $10 \mathrm{kV}$. and the quantity of electricity from 1 to 4 coulombs. Surge recorders showed that the time from start to crest of the discharge was 16 usec. Bare copper wires of 24 and 28 gauge fused on the poles nearest the tree hit. A steel culvert conducted current to the cable buried north of the road. The cable which was struck was about $\frac{1}{2}$ in. in diameter, including its lead sheath, and was enclosed in a vulcanized rubber covering about $1 / 16$ in. thick. Small puncture marks were found in the rubber where the lightning current entered the sheath. No other damage was found. 